\title{
repisälud
}

This is the peer reviewed version of the following article:

Perdiguero, E., Moiseeva, V., \& Munoz-Canoves, P. (2019). Simultaneous Isolation of Stem and Niche Cells of Skeletal Muscle: Applicability for Aging Studies. Methods in Molecular Biology, 2045, 13-23.

doi:10.1007/7651_2019_210

which has been published in final form at: https://doi.org/10.1007/7651 2019210 


\section{Simultaneous isolation of stem and niche cells of skeletal muscle: applicability for aging studies}

Eusebio Perdiguero ${ }^{1 \wedge}$, Victoria Moiseeva ${ }^{1}$, Pura Muñoz-Cánoves ${ }^{1,2,3 \wedge}$

${ }^{1}$ Cell Biology Group, Department of Experimental and Health Sciences, Pompeu Fabra University (UPF), CIBER on Neurodegenerative diseases (CIBERNED), Barcelona, Spain; ${ }^{2}$ Spanish National Center on Cardiovascular Research (CNIC), Madrid, Spain; ${ }^{3}$ Institució Catalana de Recerca i Estudis Avançats (ICREA), Barcelona, Spain.

${ }^{\wedge}$ Equal contribution

Correspondence:

Pura Muñoz-Cánoves (pura.munoz@upf.edu)

Eusebio Perdiguero (eusebio.perdiguero@upf.edu) 


\section{Summary}

The maintenance of adult stem cells in their normal quiescent state depends on intrinsic factors and extrinsic signals originating from their microenvironment (also known as the stem cell niche). In skeletal muscle, its stem cells (satellite cells) lose their regenerative potential with aging and this has been attributed, at least in part, to both age-associated changes in the satellite cells as in the niche cells, which include resident fibro-adipogenic progenitors (FAPs), macrophages and endothelial cells, among others. To understand the regenerative decline of skeletal muscle with aging there is a need for methods to specifically isolate stem and niche cells from resting muscle. Here we describe a fluorescence-activated cell sorting (FACS) protocol to simultaneously isolate discrete populations of satellite cells and niche cells from skeletal muscle of aging mice.

\section{Keywords:}

stem cell, satellite cell, niche cells, skeletal muscle, quiescence, aging, flow cytometry, enzymatic dissociation, FACS

Running title: Isolation of muscle stem and niche cells by FACS 


\section{Introduction}

Aging of skeletal muscle alters the composition of the niche and has deleterious consequences on the functionality of its stem cells, and hence on the tissue's regenerative capacity [1-3]. This age-associated decline in regenerative capacity is maximal at geriatric age $[4,5]$. For the characterization of the cellular interactions of muscle stem cell with the non-muscle niche-resident cell types, it will be mandatory to isolate these discrete cell populations in a specific way, and if possible, simultaneously, to decrease experimental variability and minimize animal use and costs (particularly in aging studies), as well as users' effort. Surely, isolation of the stem cell-niche components of muscle in young and aged mice will help understand regulatory interactions that can help to envision ways to improve aged muscle regeneration.

Satellite cells reside in a quiescent state beneath the basal lamina of myofibers until they are activated by damage or growth signals initiating a process of proliferation/differentiation or self-renewal to repair adult skeletal muscle and or replenish the stem cell pool [6-9]. Most mammalian satellite cells can be identified by expression of the paired-box transcription factor Pax7, which only labels satellite cells in skeletal muscle. Many other proteins are known to mark satellite cells, including Integrin- $\alpha 7$, M-Cadherin, Caveolin-1, CD56/NCAM, CD29/Integrin- $\beta 1$, Syndecan 3 and 4 (reviewed in $[6,10,11]$ ). However, these markers are also expressed by other interstitial cells within the muscle tissue, so combinations of different markers are used to isolate satellite cells to purity.

Other cellular populations present in the adult skeletal muscle contribute and modulate muscle regeneration, including endothelial cells, pericytes/mesoangioblasts, Pw1+ cells (known as PICs), mesenchymal progenitors normally referred as fibro-adipogenic progenitors (FAPs) and different types of hematopoietic cells which infiltrate the damaged muscle, including neutrophils, circulating blood monocytes that differentiate into inflammatory macrophages and different types of lymphoid cells (eosinophils, 
Tregs and CD8+ T cells) $[12,13]$. Interplay between all these cell types have been demonstrated to be essential for myogenesis [14-17].

Using well-known markers for different cellular populations, we have set up a procedure to isolate by fluorescence activated cell sorting (FACS) satellite cells, FAPS, macrophages and endothelial cells from resting and regeneration skeletal muscle of mice. This procedure can be used both in young/adult as in aging mice.

\section{Materials}

\subsection{Isolation of satellite cells, macrophages, FAPs and endothelial cells by FACS}

1. Surgical tools (small scissors, scalpels, fine tip forceps, hemostatic forceps) are cleaned and sterilized by autoclaving.

2. Razor blades

3. DMEM (Dulbecco's Modified Eagle Medium) high glucose, supplemented with $1 \%$ penicillin/streptomycin (P/S) and 10\% Fetal Bovine Serum (FBS).

4. Red blood cell lysis Buffer (BD Pharm Lyse, 555899)

5. FACS Buffer: Phosphate Buffered Saline (PBS) 1X, 5\% Goat Serum.

6. Digestion mix: Liberase (Roche/Sigma-Aldrich, ref. 05401127001; final 0,02\%), Dispase II (Sigma-Aldrich, D4693; final 0,05\%), $4 \mu \mathrm{L}$ stock $1 \mathrm{M} \mathrm{CaCl}_{2}$ (final 0,4 $\mathrm{mM}$ ), $50 \mu \mathrm{L}$ stock $1 \mathrm{M} \mathrm{MgCl}_{2}$ (final $5 \mathrm{mM}$ ) in $10 \mathrm{~mL}$ DMEM1\% $\mathrm{P} / \mathrm{S}$ (four limb muscles of 1 mouse require $10 \mathrm{~mL}$ of digestion mix).

7. Antibodies: PE/Cy7 anti-mouse/human Ly-6A/E (Sca-1) (Biolegend, 108114), APC/Cy7 anti-mouse F4/80 (Biolegend, 123118), $\alpha 7$-integrin R-Phycoerythrin (AbLab, 53-0010-05), APC anti-mouse CD31 (PECAM-1) (eBioscience 17-031182), BV711 Rat anti-mouse CD45 (BD Pharmingen, 563709).

8. DAPI, stock solution $1 \mathrm{mg} / \mathrm{mL}$, final concentration $1 \mu \mathrm{g} / \mathrm{mL}$.

9. $50 \mathrm{~mL}$ conical tubes (sterile).

10. A shacking water bath.

11. $100 \mu \mathrm{m}, 70 \mu \mathrm{m}$ and $40 \mu \mathrm{m}$ cell strainer filters.

12. Centrifuge with a cooling system for $15-50 \mathrm{ml}$ conical tubes

13. Centrifuge with a cooling system for $1.5 \mathrm{ml}$ tubes

14. Hemocytometer

15. Flow Cytometry analyzer (e.g. FACSAria II - BD Biosciences) 
16. Flow Cytometry analysis software: FACSDiva software (BD Biosciences, available for Windows) or FlowJo software (available for Windows and Mac http://www.flowjo.com/download-flowjo/)

\subsection{Confirmation of the identity of the distinct FACS-isolated cell populations by} $R T-q P C R$.

1. Total RNA isolation kit. (e.g. RNeasy Micro kit (Qiagen, 74004))

2. cDNA synthesis kit (e.g. SuperScript III Reverse Transcriptase (Invitrogen 1674043))

3. Quantitative PCR apparatus (e.g. LightCycler 480 System using Light Cycler 480 SYBR Green I Master reaction mix (Roche Diagnostic Corporation))

4. Specific primers for each selected mRNA (Sigma).

\section{Methods}

\subsection{Isolation of satellite cells, macrophages, FAPs and endothelial cells by FACS}

1. Euthanize mice according to institute regulations. The following steps should be performed in a tissue culture hood to in order to limit contamination (see Notes 14).

2. Skeletal muscles are dissected with small scissors from fore and hind limbs and collected in cold DMEM 1\% P/S into $50 \mathrm{~mL}$ conical tubes (see Note 5).

3. Decant all the muscles collected in a petri dish and remove DMEM $1 \% \mathrm{P} / \mathrm{S}$ completely.

4. Mince muscles with scissors.

5. Mince muscles further with razor blades.

6. Collect minced muscles into a $50 \mathrm{~mL}$ conical tube and add cold DMEM $1 \% \mathrm{P} / \mathrm{S}$. Leave muscle sediment and remove DMEM $1 \% \mathrm{P} / \mathrm{S}$, discarding floating fat pieces. Repeat this step to further clean the sample from non-muscle pieces (see Note 5.).

7. Remove DMEM $1 \% \mathrm{P} / \mathrm{S}$ as much as possible and split the minced muscle into two $50 \mathrm{~mL}$ conical tubes. 
8. Add $5 \mathrm{~mL}$ of the prepared digestion mix (Liberase/Dispase) to each tube (see Notes 6-8).

9. Incubate 1 hour at $37^{\circ} \mathrm{C}$ in a shaking water bath (see Note 9 ).

10. Centrifuge the samples at $50 \times \mathrm{g}$ for $10 \mathrm{~min}$ at $4^{\circ} \mathrm{C}$.

11. Collect the supernatant and discard the pellet (optional: the pellet can be washed and the supernatant collected and pooled with the previous one).

12. Filter the supernatant with $100 \mu \mathrm{m}$ and then $70 \mu \mathrm{m}$ cell strainer filters.

13. Centrifuge at $670 \mathrm{xg}$ for $15 \mathrm{~min}$ at $4^{\circ} \mathrm{C}$, repeat twice. The supernatant is discarded at each round and the pellet is resuspended gently in cold DMEM 1\% P/S.

14. After the $2^{\text {nd }}$ centrifugation discard supernatant and resuspend the pellet in $2 \mathrm{~mL}$ of Red blood cells lysis Buffer 1x. Incubate for 10 minutes in ice protected from light. Do not agitate.

15. Resuspend in $50 \mathrm{~mL}$ cold DMEM 1\% P/S. At this step pool the two pellets of the same mouse and filter through a $40 \mu \mathrm{M}$ cells strainer filter.

16. Centrifuge at $670 \times \mathrm{g}$ for $15 \mathrm{~min}$ at $4^{\circ} \mathrm{C}$.

17. Discard the supernatant and resuspend the pellet in $1 \mathrm{~mL}$ of cold DMEM $1 \% \mathrm{P} / \mathrm{S}$.

18. Count the number of cells for each sample (see Note 10)

19. Centrifuge at $670 \times \mathrm{g}$ for $15 \mathrm{~min}$ at $4^{\circ} \mathrm{C}$ and resuspend the pellet at $1 \cdot 10^{4} \mathrm{cells} / \mu \mathrm{l}$ $\left(1 \cdot 10^{6}\right.$ cells in $\left.100 \mu l\right)$ in FACS Buffer.

20. Incubate the cells with antibodies for $30 \mathrm{~min}$ in ice, protected from light. All antibodies are diluted at ratio 1:200 (see Note 11).

21. Centrifuge at $670 \times \mathrm{g}$ for $15 \mathrm{~min}$ at $4^{\circ} \mathrm{C}$.

22. Discard the supernatant and resuspend the cell bulk in $1 \mathrm{~mL}$ of FACS Buffer for sample sorting.

23. Add DAPI (final concentration $1 \mu \mathrm{g} / \mathrm{mL}$ ) 5 min prior FACS to detect and exclude dead cells. Filter the sample through a test tube with cell Strainer cap to eliminate cell aggregation. The sample is now ready to be analyzed by FACS. 
24. We typically use the FACSAria II instrument for sorting, and we analyze the data using the FACSDiva or FlowJo software

25. Analyze unstained control, single stained and fluorescence-minus one (FMO) controls to set up the gating scheme for all cellular populations (see Note 12).

26. Analyze the samples. Cell granularity (side scatter, SSC), cell size (forward scatter, FSC) and DAPI staining are used to gate the events corresponding to live cells. Antibody combinations are then used to define all populations, see Table 1 and Figure 1 for a representative example (see Note 13).

\subsection{EX vivo confirmation of the identity of the distinct FACS-isolated cell populations by $R T-q P C R$.}

Specific mRNAs expressed by each population allow demonstration of a successful isolation protocol (see Figure 2).

1. After FACS (section 3.1), cells may be collected Eppendorf tubes with $500 \mu \mathrm{l}$ of FACS Buffer at $4^{\circ} \mathrm{C}$.

2. Centrifuge Eppendorf tubes at $14.000 \times \mathrm{g}$ for $5 \mathrm{~min}$.

3. Remove supernatant (see Note 14).

4. Perform total RNA extraction of each cell population using RNeasy Micro kit following manufacturer's protocol.

5. Complementary DNA (cDNA) is synthesized from total RNA using SuperScript III Reverse Transcriptase according to manufacturer's protocol.

6. Real-time PCR reactions are performed on a LightCycler 480 System using Light Cycler 480 SYBR Green I Master reaction mix and specific primers.

7. Thermocycling conditions: initial step of $10 \mathrm{~min}$ at $95^{\circ} \mathrm{C}$, then 50 cycles of $15 \mathrm{~s}$ denaturation at $94^{\circ} \mathrm{C}, 10 \mathrm{~s}$ annealing at $60^{\circ} \mathrm{C}$ and $15 \mathrm{~s}$ extension at $72{ }^{\circ} \mathrm{C}$.

8. Reactions must be run in triplicate, and automatically detected threshold cycle (Ct) values are compared between samples. 
9. Transcripts of the ribosomal protein L7 or GAPDH housekeeping genes can be used as endogenous control, with each unknown sample normalized to L7 or GAPDH content.

10. Primers used to confirm each cell populations of interest (see Table 2).

\section{Notes}

1. Anesthetize mice using approved protocols in your institution. Spray skin of the mouse with $70 \%$ ethanol. Cut and remove the skin and expose the fore-limb and hind-limb muscles.

2. Classification of mice according to age: Young (2-3 months-old), Adult (6-8 months-old ), Old (18-24 months-old), Geriatric (older than 28 months of age) [4].

3. For aging studies, as mouse mortality starts to increase around 18 months of age, increasing the number of mice cohorts to study old and geriatric age is highly recommended.

4. As sarcopenia and fibrosis increase with age [18], the amount of tissue obtained from old and geriatric mice is lower in comparison to young mice. In consequence, samples from old and geriatric animals provide lower cell yield. For aging studies, increasing the number of mice (i.e. using pools) to sort cells at old and geriatric age is recommended.

5. To avoid cross-contamination from cells types from other close-by tissues, fine dissection technique should be master to exclude adipose tissue (white fat), nerves and tendons. Remaining debris after the digestion, which includes tendons, obstruct cell strainers during sample filtration steps.

6. Collagenase $\mathrm{D}$ can be employed instead of Liberase in the digestion mix. However, the use of Collagenase $D$ requires a multi-step protocol while 
Liberase allows faster, one-step procedure. Thus, we propose digestion with Liberase for skeletal muscle tissue.

7. Trypsin has been shown to affect the integrity of cell surface proteins on mammalian cells [19]. The endothelial cell receptor CD31 is particularly susceptible to proteolytic cleavage [20]. Therefore, tissue digestion with trypsin usage is not recommended for this FACS protocol.

8. A maximum of $1 \mathrm{~g}$ of tissue should be digested per tube, otherwise the digestion will provide lower cell yield.

9. Digestion time can be prolonged to increase its efficiency, especially, in the case of muscle tissue obtained from old and geriatric animals. However, sustained digestion may increase cell mortality, so we suggest do not exceed 2 hours of digestion.

10. Count cells manually using and hemocytometer (i.e. Neubauer chamber) or any the available automatic cell counter systems.

11. It is feasible to include additional positive satellite cell-surface markers to this panel in order to increase the purity of the sorted satellite cell population. The antibody can be conjugated to FITC fluorochrome to avoid interference with the rest of cell-surface markers used in this protocol. For this purpose, CD34, CXCR4, VCAM, SM/C2.6 cell-surface markers can be used [21-25].

12. Several controls are required to establish the correct gating of cell populations in the FACS machine:

- Negative control: an unstained cell sample should be analyzed to determine the voltage of the lasers and autofluorescence of the sample.

- Single stained controls: individual staining with each antibody conjugated to its fluorescent dye. This control is needed for compensation, a technique used to remove false signal resulting from spectral overlap between two fluorochromes. For example, the Sca1PE/Cy7 and F4/80-APC/Cy7 antibodies used in this protocol have high 
spectral overlap, therefore, the compensation should be done properly to avoid non-specific cell sorting.

- FMO (Fluorescence Minus One) controls: staining with all antibodies except one should be done for each color used in the panel. This type of staining is needed to discriminate properly the cell populations.

13. Using 4-way purity precision mode, we can separate satellite cells, macrophages, FAPs and endothelial cells simultaneously.

14. Cell pellet or extracted RNA can be stored at $-80^{\circ} \mathrm{C}$ until RNA isolation or cDNA synthesis respectively.

\section{References}

1. Sousa-Victor P, Garcia-Prat L, Serrano AL, Perdiguero E, Munoz-Canoves P (2015) Muscle stem cell aging: regulation and rejuvenation. Trends Endocrinol Metab 26 (6):287-296. doi:10.1016/j.tem.2015.03.006

2. Mashinchian O, Pisconti A, Le Moal E, Bentzinger CF (2018) The Muscle Stem Cell Niche in Health and Disease. Curr Top Dev Biol 126:23-65. doi:10.1016/bs.ctdb.2017.08.003

3. Almada AE, Wagers AJ (2016) Molecular circuitry of stem cell fate in skeletal muscle regeneration, ageing and disease. Nat Rev Mol Cell Biol. doi:10.1038/nrm.2016.7

4. Sousa-Victor P, Gutarra S, Garcia-Prat L, Rodriguez-Ubreva J, Ortet L, Ruiz-Bonilla V, Jardi M, Ballestar E, Gonzalez S, Serrano AL, Perdiguero E, Munoz-Canoves P (2014) Geriatric muscle stem cells switch reversible quiescence into senescence. Nature 506 (7488):316-321. doi:10.1038/nature13013

5. Garcia-Prat L, Martinez-Vicente M, Perdiguero E, Ortet L, Rodriguez-Ubreva J, Rebollo E, Ruiz-Bonilla V, Gutarra S, Ballestar E, Serrano AL, Sandri M, MunozCanoves P (2016) Autophagy maintains stemness by preventing senescence. Nature 529 (7584):37-42. doi:10.1038/nature16187 
6. Yin H, Price F, Rudnicki MA (2013) Satellite cells and the muscle stem cell niche. Physiol Rev 93 (1):23-67. doi:10.1152/physrev.00043.2011

7. Relaix F, Zammit PS (2012) Satellite cells are essential for skeletal muscle regeneration: the cell on the edge returns centre stage. Development 139 (16):28452856. doi:10.1242/dev.069088

8. Gros J, Manceau M, Thome V, Marcelle C (2005) A common somitic origin for embryonic muscle progenitors and satellite cells. Nature 435 (7044):954-958. doi:10.1038/nature03572

9. Cornelison D, Perdiguero E (2017) Muscle Stem Cells: A Model System for Adult Stem Cell Biology. Methods Mol Biol 1556:3-19. doi:10.1007/978-1-4939-6771-1_1

10. Boldrin L, Muntoni F, Morgan JE (2010) Are human and mouse satellite cells really the same? The journal of histochemistry and cytochemistry : official journal of the Histochemistry Society 58 (11):941-955. doi:10.1369/jhc.2010.956201

11. Tedesco FS, Dellavalle A, Diaz-Manera J, Messina G, Cossu G (2010) Repairing skeletal muscle: regenerative potential of skeletal muscle stem cells. J Clin Invest 120 (1):11-19. doi:10.1172/JCI40373

12. Tedesco FS, Moyle LA, Perdiguero E (2017) Muscle Interstitial Cells: A Brief Field Guide to Non-satellite Cell Populations in Skeletal Muscle. Methods Mol Biol 1556:129147. doi:10.1007/978-1-4939-6771-1_7

13. Tidball JG (2017) Regulation of muscle growth and regeneration by the immune system. Nat Rev Immunol 17 (3):165-178. doi:10.1038/nri.2016.150

14. Latroche C, Weiss-Gayet M, Muller L, Gitiaux C, Leblanc P, Liot S, Ben-Larbi S, Abou-Khalil R, Verger N, Bardot P, Magnan M, Chretien F, Mounier R, Germain S, Chazaud B (2017) Coupling between Myogenesis and Angiogenesis during Skeletal Muscle Regeneration Is Stimulated by Restorative Macrophages. Stem cell reports 9 (6):2018-2033. doi:10.1016/j.stemcr.2017.10.027

15. Lemos DR, Babaeijandaghi F, Low M, Chang CK, Lee ST, Fiore D, Zhang RH, Natarajan A, Nedospasov SA, Rossi FM (2015) Nilotinib reduces muscle fibrosis in 
chronic muscle injury by promoting TNF-mediated apoptosis of fibro/adipogenic progenitors. Nat Med 21 (7):786-794. doi:10.1038/nm.3869

16. Kuswanto W, Burzyn D, Panduro M, Wang KK, Jang YC, Wagers AJ, Benoist C, Mathis D (2016) Poor Repair of Skeletal Muscle in Aging Mice Reflects a Defect in Local, Interleukin-33-Dependent Accumulation of Regulatory T Cells. Immunity 44 (2):355-367. doi:10.1016/j.immuni.2016.01.009

17. Panduro M, Benoist C, Mathis D (2018) Treg cells limit IFN-gamma production to control macrophage accrual and phenotype during skeletal muscle regeneration. Proceedings of the National Academy of Sciences of the United States of America 115 (11):E2585-E2593. doi:10.1073/pnas.1800618115

18. Brack AS, Conboy MJ, Roy S, Lee M, Kuo CJ, Keller C, Rando TA (2007) Increased Wnt signaling during aging alters muscle stem cell fate and increases fibrosis. Science 317 (5839):807-810. doi:10.1126/science.1144090

19. Huang HL, Hsing HW, Lai TC, Chen YW, Lee TR, Chan HT, Lyu PC, Wu CL, Lu YC, Lin ST, Lin CW, Lai CH, Chang HT, Chou HC, Chan HL (2010) Trypsin-induced proteome alteration during cell subculture in mammalian cells. J Biomed Sci 17:36. doi:10.1186/1423-0127-17-36

20. Gayraud-Morel B, Pala F, Sakai H, Tajbakhsh S (2017) Isolation of Muscle Stem Cells from Mouse Skeletal Muscle. Methods Mol Biol 1556:23-39. doi:10.1007/978-14939-6771-1_2

21. Montarras D, Morgan J, Collins C, Relaix F, Zaffran S, Cumano A, Partridge T, Buckingham M (2005) Direct isolation of satellite cells for skeletal muscle regeneration. Science 309 (5743):2064-2067. doi:1114758 [pii]

10.1126/science. 1114758

22. Chakkalakal JV, Jones KM, Basson MA, Brack AS (2012) The aged niche disrupts muscle stem cell quiescence. Nature 490 (7420):355-360. doi:10.1038/nature11438 
23. Cheung TH, Quach NL, Charville GW, Liu L, Park L, Edalati A, Yoo B, Hoang P, Rando TA (2012) Maintenance of muscle stem-cell quiescence by microRNA-489. Nature 482 (7386):524-528. doi:10.1038/nature10834

24. Fukada S, Higuchi S, Segawa M, Koda K, Yamamoto Y, Tsujikawa K, Kohama Y, Uezumi A, Imamura M, Miyagoe-Suzuki Y, Takeda S, Yamamoto H (2004) Purification and cell-surface marker characterization of quiescent satellite cells from murine skeletal muscle by a novel monoclonal antibody. Exp Cell Res 296 (2):245-255 doi:10.1016/j.yexcr.2004.02.018

25. Sherwood RI, Christensen JL, Conboy IM, Conboy MJ, Rando TA, Weissman IL, Wagers AJ (2004) Isolation of adult mouse myogenic progenitors: functional heterogeneity of cells within and engrafting skeletal muscle. Cell 119 (4):543-554. doi:10.1016/j.cell.2004.10.021 
Tables:

\begin{tabular}{|c|c|c|}
\hline Cell population & Positive selection & Negative selection \\
\hline Satellite cells & $\alpha 7$-integrin ${ }^{+}$ & $\mathrm{CD}^{\circ} 5^{-}, \mathrm{F} 4 / 80^{-}, \mathrm{CD} 31^{-}$ \\
\hline Macrophages & $\mathrm{CD}_{45^{+}}, \mathrm{F} 4 / 80^{+}$ & - \\
\hline FAPs & Sca $1^{+}$ & $\begin{array}{c}\text { CD45-, F4/80-, CD31- }^{-} \text {, } \\
\alpha 7 \text {-integrin- }\end{array}$ \\
\hline Endothelial cells & CD31+, $\alpha 7$-integrin ${ }^{+}$ & $\mathrm{CD}_{45}{ }^{-}, \mathrm{F} 4 / 80^{-}$ \\
\hline
\end{tabular}

Table 1. Positive and negative selection of cell surface markers used to discriminate each cell population of interest.

\begin{tabular}{|c|c|c|}
\hline & Forward & Reverse \\
\hline $\mathbf{F 4 / 8 0}$ & CCCCAGTGTCCTTACAGAGTG & GTGCCCAGAGTGGATGTCT \\
\hline CD14 & AAAGAAACTGAAGCCTTTC & AGCAACAAGCCAAGCACAC \\
\hline TLR4 & GCCACCAGTTACAGATCGTC & AGAGAAACTTCCTGGGGAAA \\
\hline Pax7 & GTGTCTCCAAGATTCTGTGCCG & CAATCTTTTTCTCCACATCCGG \\
\hline Myf5 & CTGTCTGGTCCCGAAAGAAC & AAGCAATCCAAGCTGGACAC \\
\hline CD31/PECAM & GTACGAGGTGAAGGTGCAT & AATGTGCAGCTGGTCCCC \\
\hline VE-Cadh & AAATGAATCGCTGCCCCACT & TGTTAGCATCGACCCCGAAG \\
\hline Tie1 & CAGGCACAGCAGGTTGTAGA & GTGCCACCATTTTGACACTG \\
\hline PDGFR $\alpha$ & TGGCATGATGGTCGATTCTA & CGCTGAGGTGGTAGAAGGAG \\
\hline CD36 & ATGGGCTGTGATCGGAACTG & GTCTTCCCAATAAGCATGTCTCC \\
\hline
\end{tabular}

Table 2. Primers used for RT-qPCR to confirm identity of each cell population sorted with proposed FACS panel. 
Figure legends:
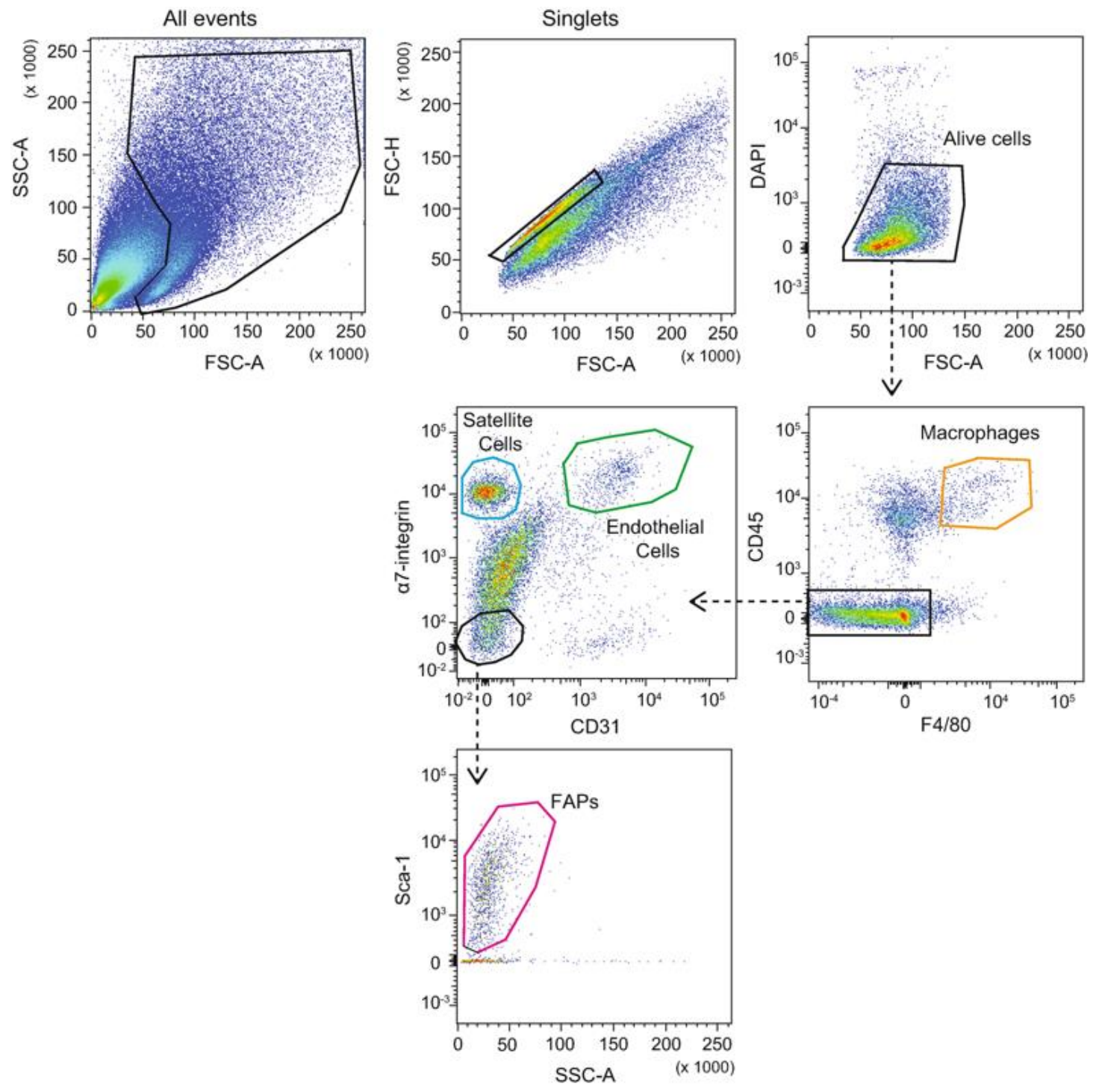

Figure 1. Representative example of the FACS strategy and gating scheme to isolate satellite cells, macrophages, FAPs and endothelial cells from resting muscles of wild type mice. All singlet events are selected using forward (FSC) and side scatter (SSC) detectors. Subsequently, alive cells are chosen by DAPI. From there, macrophages (are identified as $\mathrm{CD} 45^{+} \mathrm{F} 4 / 80^{+}$double positive cells. Satellite cells are gated from $\mathrm{CD}_{45}, \mathrm{~F} 4 / 80^{-}$population as $\alpha 7$-integrin ${ }^{+}$meanwhile endothelial cells as $\alpha 7$-integrin ${ }^{+}$and CD31+. Finally, FAPs are sorted by Sca $1^{+}$staining from $\alpha 7$ integrin- CD31- cell population. Arrows show the sequence of gating used. 

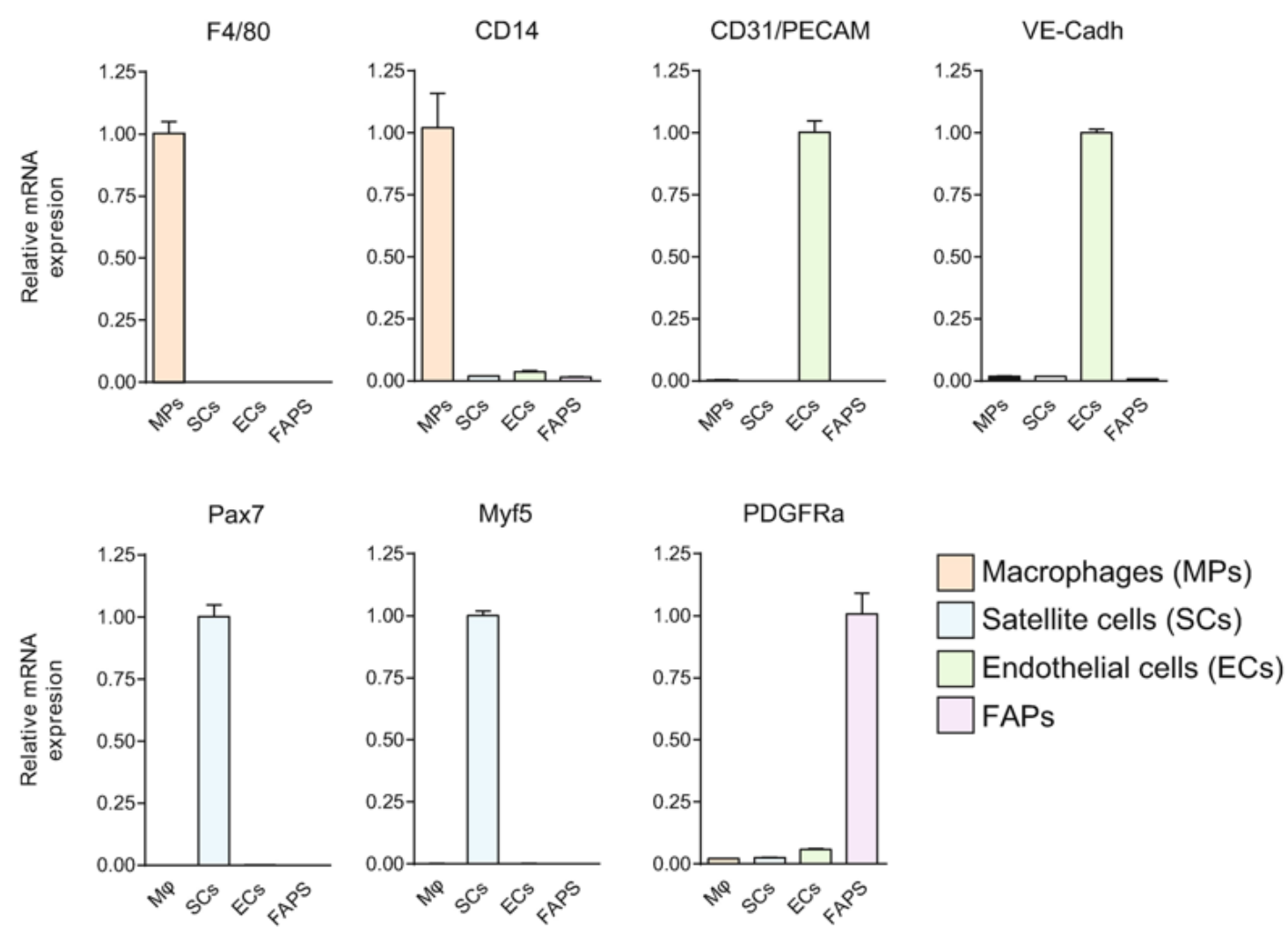

Figure 2. Representative example ex vivo confirmation of the identity of the distinct FACS-isolated cell populations by RT-qPCR. Comparative qPCR analysis with indicated genes in isolated cellular populations. Specific genes for macrophages are F4/89 and CD14, for endothelial cells are CD31 (also known as PECAM) and VECadherin, for satellite cells are Pax7 and Myf5, and for FAPS PDGFRa. Means \pm SEM of at least three experiments.

\section{Acknowledgements}

Work in the authors' laboratory has been supported by the Spanish Ministry of Science, Innovation and Universities, Spain (grant SAF2015-67369-R; and SAF 2015-70270REDT, a María de Maeztu Unit of Excellence award to UPF [MDM-2014-0370], and a Severo Ochoa Center of Excellence award to the CNIC [SEV-2015-0505]), the UPFCNIC collaboration agreement, ERC-2016-AdG-741966, H2020-SC1-BHC-20182020/H2020-SC1-2018, La Caixa-HR17-00040, AFM, Fundació MaratóTV3, and DPPE. V.M is recipient of a FPI predoctoral fellowship. 